\title{
Production and quality evaluation of extruded snack from blends of bambara groundnut flour, cassava starch, and corn bran flour
}

\author{
O.H. Ogunmuyiwa, A.A. Adebowale , O.P. Sobukola, O.O. Onabanjo, A.O. Obadina, M.O. Adegunwa, \\ O.E. Kajihausa, L.O. Sanni, T. Keith
}

Funding information European Commission Food Security Thematic Programme (FSTP) Component 1—Research and Technology

\section{Abstract}

Protein dense, fiber-rich extruded snacks were produced from blend of bambara groundnut flour, cassava starch, and corn bran flour using a single screw cooking extruder. The snacks were analyzed for their physical properties and proximate composition using standard laboratory procedures. The expansion ratio, specific volume, breaking force, and breaking strength index (BSI) of the snacks ranged from 0.85 to 1.22 , 0.75 to $1.30 \mathrm{~g} / \mathrm{cm}^{3}, 3.95$ to $36.45 \mathrm{~N}$, and 0.99 to $9.11 \mathrm{~N} / \mathrm{mm}$, respectively. The breaking force and BSI were high and increased at increasing levels of cassava starch and corn bran inclusion. Moisture, protein, fat, carbohydrates, crude fiber, and total dietary fiber contents of the snacks were 5.40-10.80, 3.26-17.62, 0.68$10.35 \%, 60.56-85.03,0.32-4.78$, and $7.36-28.74 \%$, respectively. The study revealed a great potential of obtaining a nutrient dense extruded snack from underutilized plant commodity (bambara groundnut) and waste from corn milling (corn bran). 
Findings from this study will find numerous applications in gluten-free products. It is also capable of enhancing the productivity and utilization of bambara groundnut (an underutilized nutritious legume). The study also attempted to add value to waste product of corn milling (corn bran).

\section{Introduction}

Bambara groundnut ( Vigna subterranean [L.]) Verdc. Fabaceae, is an indigenous legume of African origin mainly cultivated by subsistence farmers. The seed is very nutritious but underutilized legume, which is potentially very rich in proteins and minerals (Okpuzor, Ogbunugafor, Okafor, \& Sofidiya, 2010). The seed is consumed as food in different forms in different parts of the world. The young fresh seeds can be boiled and eaten as a snack similar to boiled peanuts. Bambara groundnut seed could be made into pudding locally called Moinmoin or Okpa (bean porridge) in some parts of Nigeria (Adegunwa, Adebowale, Bakare, \& Kalejaiye, 2014). Okpuzor et al. (2010) reported that in Zambia, Bambara groundnut seed flour is used in bread making. The nut could also be used for making milk (Poulter \& Caygill, 2006). Bambara groundnut seed makes a complete food, as it contains sufficient quantities of protein, carbohydrate, and fat (Bamshaiye, Adegbola, \& Bamishaiye, 2010). Bambara groundnut has been reported to contain carbohydrates (54.5-69.3\%), proteins $(17-24.6 \%)$, fat $(5.3-7.8 \%)$, and calories $(367-414 \mathrm{kcal} / 100 \mathrm{~g})$ and is a good source of calcium, iron, and potassium. It is also very high in methionine, an essential sulfur-containing amino acid (Bamshaiye et al., 2010). As an underutilized crop, bambara groundnut has not received a sustained research efforts in terms of industrial utilization.

Starch is one of the most abundant substances in many plants, renewable, and almost unlimited resources (Pandey et al., 2000). Cassava root contains about 1\% protein and 30-35\% starch on a dry weight basis, thus a predominantly starchy food. Cassava starch has a low gelatinization temperature $\left(65-70^{\circ} \mathrm{C}\right)$, a rapid increase in viscosity after gelatinization, and forms a clear, soft gel with better cold stability, but a very cohesive texture. It is ranked very high among starchy staples because it gives a carbohydrate production, which is about $40 \%$ higher than rice and $25 \%$ more than maize (Nyerhovwo, 2004). Being a human food, it has been criticized for its low and poor quality protein content. Cassava starch is recommended for improving expansion in extruded snacks.

Dietary fiber is that fraction of the edible parts of plants or their extracts, or synthetic analogs, that are resistant to digestion and absorption in the small intestine, usually with complete or partial fermentation in the large intestine. Fiber intake through the consumption of foods rich in dietary components, such as fresh vegetables, fruits, whole grains, and nuts, is associated with reduction in plasma and low-density lipoprotein cholesterol, attenuating glycemic and insulin response, increasing stool bulk and improving laxation (Schneeman, 1998). Corn bran as a by-product of dry and wet milling of corn is an important and valuable source of dietary fiber. It has a high dietary fiber content (up to $900 \mathrm{~g} / \mathrm{kg}$ ) indicating that it can be used at lower levels than other products to provide an equivalent fiber content to finished food product (Duxbury, 1988). However, it is usually thrown away or fed to livestock.

Extrusion cooking is a high-temperature, short-time process in which moistened, expansive, starchy and/or proteinacious food materials are plasticized and cooked in a tube by a combination of moisture, pressure, temperature, and mechanical shear, resulting in molecular transformation and chemical reactions (Castells, Marin, Sanchis, \& Ramos, 2005). Extrusion process has found numerous applications such as increasing numbers of ready-to-eat cereals, and one main advantage is the capability to produce a wide range of finished products with minimum processing times and inexpensive raw materials (Riaz, 2000). The objective of this study 


\section{Materials and methods}

Food grade cassava starch was purchased from Matna Foods Company Limited (Akure, Ondo State, Nigeria). Corn bran was purchased from corn millers at Bodija market in Ibadan, Oyo State, Nigeria. Being a product of semiwet milling, it was dried in a cabinet dryer at $65^{\circ} \mathrm{C}$ for $12 \mathrm{~h}$ to moisture content of about $8 \%$ and then packaged in an airtight plastic container. Bambara groundnut seeds were purchased from Bodija market in Ibadan, Oyo State, Nigeria, and were processed into flour by adopting the method of Olapade and Adetuyi (2007). The flow chart for the production of bambara groundnut flour is shown in Figure 1.

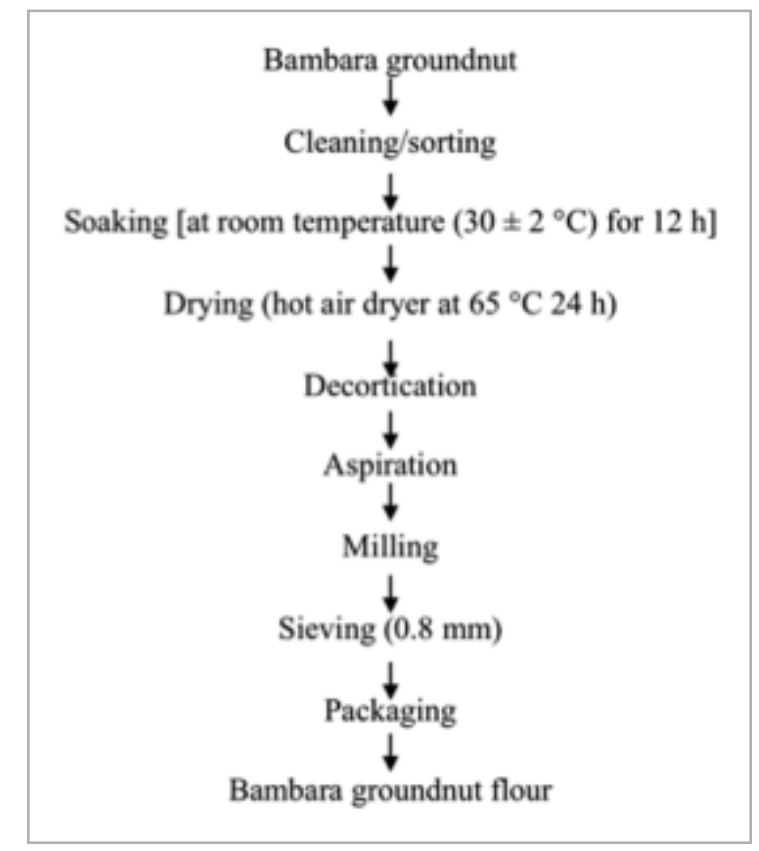

\section{Figure 1.}

Open in figure viewer

Flow chart for the preparation of bambara groundnut flour. Source : From "Comparison of different methods of producing bambara (Voandzeia subterranean L. Thou) flours for preparation of 'moin moin'," by A. Olapade and D. O. Adetuyi, 2007, Nigerian Food Journal , 25, pp. 150-157

\subsection{Experimental design}

A simplex centroid mixture design from Design-Expert 6.0.8 (Stat-Ease, Inc., Mineaplolis) software was used to formulate the ratios of the flours in the mixture of the three components where $X_{1}, X_{2}$, and $X_{3}$ represent bambara groundnut flour, corn bran, and cassava starch, respectively. Fourteen experimental runs (Table 1) were generated with the total of the proportions of each component in a run representing $100 \%$.

Table 1. Experimental design with three components

\begin{tabular}{|l|l|l|l|}
\hline Runs & $x_{1}$ & $x_{2}$ & $x_{3}$ \\
\hline
\end{tabular}




$\begin{array}{llll}2 & 0.10 & 0.10 & 0.80 \\ 3 & 0.10 & 0.80 & 0.10 \\ 4 & 0.50 & 0.00 & 0.50 \\ 5 & 0.00 & 0.50 & 0.50 \\ 6 & 0.50 & 0.50 & 0.00 \\ 7 & 0.33 & 0.33 & 0.33 \\ 8 & 0.67 & 0.17 & 0.17 \\ 9 & 0.17 & 0.17 & 0.17 \\ 10 & 0.17 & 0.67 & 0.50 \\ 11 & 0.50 & 0.00 & 0.33 \\ 12 & 0.33 & 0.33 & 0.00 \\ 13 & 0.50 & 0.50 & 0.10 \\ \text { Bambara nut flour }\left(X_{1}\right), \text { corn bran }\left(X_{2}\right), \text { and cassava starch }\left(X_{3}\right) ; X_{1}+X_{2}+X_{3}=1 \text { or } 100 \% . & \end{array}$

\subsection{Composite blends preparation}

According to the ratios, each combination was calculated and weighed with a Mettler Toledo PB153-S weighing balance, to make up a total of $200 \mathrm{~g}$, which was used for the production of the extruded snacks. The weighed mixtures were then homogenized and sealed in labeled airtight plastic containers for analyses. The ratios of the 14 experimental runs are presented in Table 1.

\subsection{Extrusion of the snack}

A single screw cooking extruder with the screw length of $37 \mathrm{~cm}$, the screw length per diameter of 16.43:1, and the screw diameter of $18.5 \mathrm{~mm}$ was used to produce the extruded snacks. The extruder composed of two sections: the transmission and the die zones. The barrel section was heated with band heater (Sobukola, Babajide, \& Ogunsade, 2012). Each composite blend was mixed with a calculated amount of water for desired moisture content. The dough was allowed to condition for $10 \mathrm{~min}$ at room temperature prior to extrusion. The machine was preheated at a temperature of $70^{\circ} \mathrm{C}$ before feeding the slurry into the extruder hopper. Extrusion was carried out at 2,500 rpm screw speed with a die of diameter $5 \mathrm{~mm}$. The extrudates were cut into pieces of approximately $5 \mathrm{~cm}$ each and dried in a Genlab drying cabinet at $65^{\circ} \mathrm{C}$ for $18 \mathrm{~h}$ after which they were allowed to 


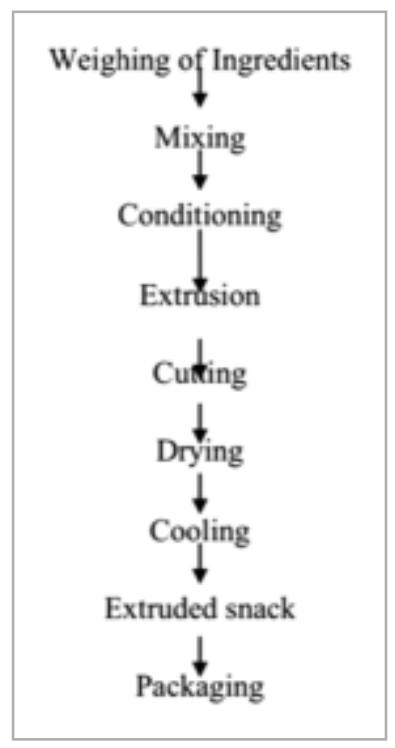

\section{Figure 2.}

Open in figure viewer

Flow chart for the preparation of extruded snacks

\subsection{Determination of physical properties of the extruded snacks}

\subsubsection{Expansion ratio}

Expansion ratio, which is the ratio of the diameter of the extrudate to the die diameter, was determined according to the method of Fan, Mitchell, and Blanchard (1996). The extrudate diameter was taken as the mean of 10 random measurements. Each cut and dried extrudate diameter was measured with the use of a Hilka micrometer screw gauge and the mean of the diameters of 10 pieces determined.

Expansion ratio $=\frac{\text { extrudate diameter }}{\text { die diameter }}$

\subsubsection{Specific volume}

This was determined using water displacement method as described by Hashimoto (1996). Each piece of the extrudate was weighed, bathed twice in melted paraffin wax, and allowed to cool overnight. The pieces were then carefully packed and suspended in a volumetric water receptacle. The volume of water displaced represented the extrudate volume. The extrudate-specific volume in gram per cubic centimeter was calculated as

Specific volume $=\frac{\text { weight of snack }(\mathrm{g})}{\text { volume of } \operatorname{snack}\left(\mathrm{cm}^{3}\right)}$.

\subsubsection{Textural properties}

The hardness (peak force during first compression) and fracturability (force at first yield break) of the snacks were determined using universal texture analyzer (Testometer AX M500). The measurement was taken at a test speed of $20 \mathrm{~mm} / \mathrm{min}$, and a preload head of $0.001 \mathrm{~N}$ with the distance between two supports being $20 \mathrm{~mm}$. Each 
snack was cut to determine the texture properties such as force at peak, force at break, bending strength at peak, and bending strength at break. Breaking strength index (BSI) is the ratio of the force at peak to the

extrudate diameter (Onwulata, Konstance, Smith, \& Holsinger, 2001)

$\mathrm{BSI}=\frac{\text { Force at peak }(\mathrm{N})}{\text { Extrudate diameter }(\mathrm{mm})}$.

\subsection{Determination of proximate composition of the extruded snacks}

The moisture, protein, total dietary fiber ash, and fat contents of the snacks were determined using the Association of Analytical Chemists (AOAC, 2000) method. The crude fiber content was determined using Fiber Cap $^{\text {TM }}$ 2021/2023 System according to AOAC 978.10, AACC 32-10, and AOCS Ba 6-84. Carbohydrate content was obtained by difference

$\%$ carbohydrate $=100-(\%$ moisture $+\%$ protein $+\%$ crude fiber $+\%$ ash $)$.

\subsection{Statistical analysis}

Data obtained were subjected to analysis of variance at $5 \%$ significance level using Statistical Package for Social Sciences by International Business Machines Version 21 and Design-Expert 6.0.8 (Stat-Ease, Inc., Mineaplolis) software. Significant means were separated using Duncan's multiple range test. A second-order polynomial regression model for the dependent variables was fitted for the experimental data for each response, where $X_{i}, X_{i} X_{i}$, and $X_{i} X_{j}$ are linear, quadratic, and interaction effects respectively, of the input variables, which influence the response $Y_{i}, \beta_{0}, \beta_{i}, \beta_{i i}$, and $\beta_{i j}$ are the regression coefficients to be determined $Y_{i}=\beta_{0}+\sum_{i=1}^{3} \beta_{i} X_{i}+\sum_{i=1}^{3} \beta_{i i} X_{i} X_{i}+\sum_{i<j=1}^{3} X_{i} X_{j}$

\section{Results and discussion}

\subsection{Physical properties of the extruded snacks}

The surface plot for the physical properties of the extruded snacks is presented in Figure 3. The expansion ratio of the snacks ranged from 0.85 to 1.22 . It was high and increased at increasing levels of cassava starch and corn bran. As shown in Table 2, ingredient combinations had significant $(p<0.05)$ positive linear effects on expansion ratio $(p<0.05)$. Corn bran and cassava starch inclusion had a negative interactive effect on the expansion ratio of the snacks. Gelatinization of cassava starch was perceived to improve the expansion of the extrudates (regression coefficient $=1.30$, expansion ratio $R^{2}=0.8553$ ). There was significant difference in the expansion ratio, lightness, redness, and yellowness of the snacks $(p<0.05)$. The specific volume, breaking force, and BSI of the snacks showed no significant difference $(p>0.05)$. High expansion ratio implies increased porosity of the product either with a large number of gas cells or with a number of large gas cells. Expansion ratio has an effect on increasing the brittleness of the product. Expansion of extruded starch-based products (either as radial or as longitudinal) is a result of extensive flash-off of internal moisture and also the flow properties of molten mass, which is a function of the degree of gelatinization (Chinnaswamy \& Hanna, 1988). The reduction in expansion ratio as observed with increase in bambara groundnut inclusion could be explained by its rheological properties and the dough elasticity. Supat, Kamolwan, Anuvat, Phaisan, and Ray (2009) also reported that increased protein content in feed material produced a less expanded product. Mendonca, Grossmann, and Verhe (2000), reported deleterious effect of corn bran on radial expansion of extruded corn bran with glycerol monostearate as an additive. This was explained by inert components such as fiber, which 


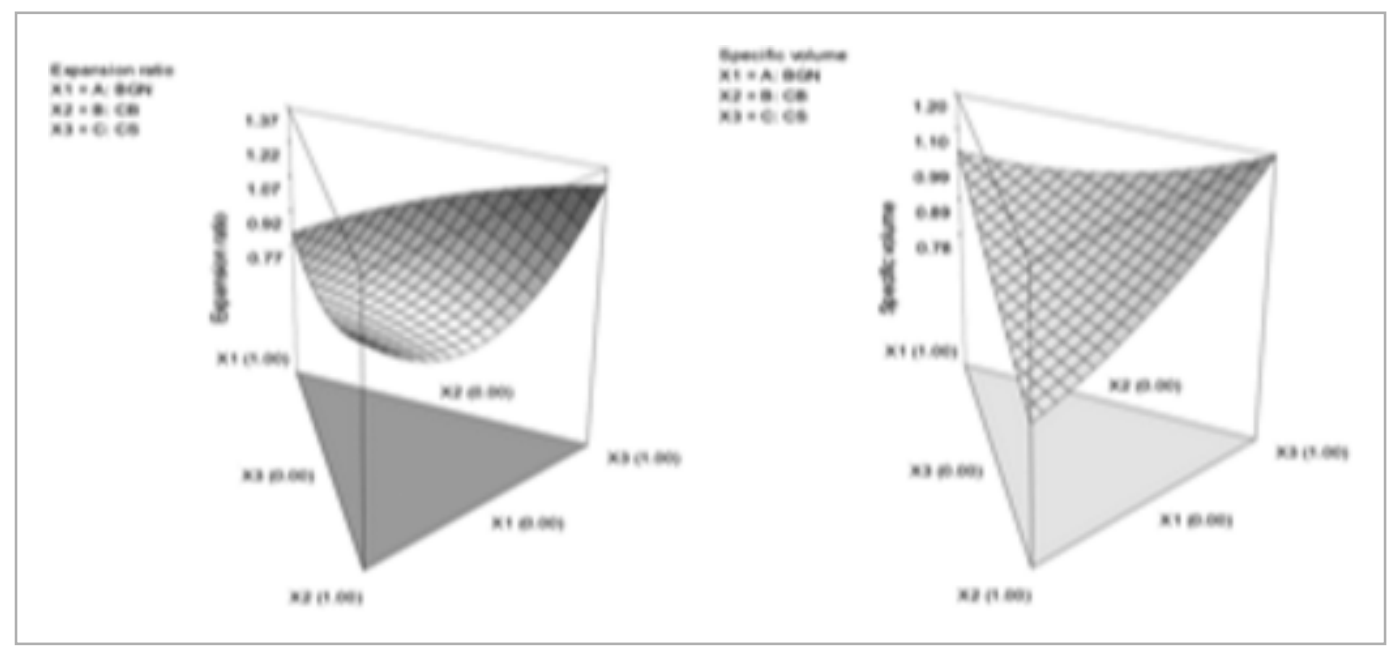

\section{Figure 3.}

Open in figure viewer

Surface plots showing expansion ratio and specific volume of bambara flour-corn bran-cassava starch extruded snacks

Table 2. Regression coefficients for the physical properties of the extruded snacks

\begin{tabular}{|c|c|c|c|c|}
\hline Components & $Y_{1}$ & $Y_{2}$ & $Y_{3}$ & $Y_{4}$ \\
\hline$x_{1}$ & $0.83^{*}$ & 1.04 * & $5.23^{*}$ & $1.60^{*}$ \\
\hline$x_{2}$ & $1.12^{*}$ & $0.78^{*}$ & $20.01^{*}$ & $4.70^{*}$ \\
\hline$x_{3}$ & 1.30 * & 1.20 * & $34.46^{*}$ & $8.83^{*}$ \\
\hline$x_{1} x_{2}$ & -0.45 & -0.029 & -38.29 & -9.49 \\
\hline$x_{1} x_{3}$ & 0.23 & -0.23 & 6.45 & -1.66 \\
\hline$x_{2} X_{3}$ & $-1.29^{*}$ & -0.22 & -91.96 & -22.07 \\
\hline$R^{2}$ & 0.8553 & 0.5005 & 0.6308 & 0.6236 \\
\hline$F$ value & 9.46 & 1.60 & 2.73 & 2.65 \\
\hline$p>F$ & 0.0033 & 0.2631 & 0.0994 & 0.1061 \\
\hline Pred $R^{2}$ & 0.3691 & -0.6749 & -0.2386 & -0.2159 \\
\hline Adj $R^{2}$ & 0.7648 & 0.1883 & 0.4000 & 0.3884 \\
\hline
\end{tabular}


$X_{1}$, bambara flour; $X_{2}$, corn bran; $X_{3}$, cassava starch; $Y_{1}$, expansion ratio; $Y_{2}$, specific volume; $Y_{3}$, breaking force; $Y_{4}$, breaking strength index.

*Significant at $p<0.05$.

The specific volume of the extrudates ranged from 0.75 to $1.30 \mathrm{~g} / \mathrm{cm}^{3}$ and was highest at high level of cassava starch inclusion but decreased with corn bran inclusion. The reduction in the specific volume of the snacks with increasing corn bran inclusion could be attributed to the high fiber component, which has the ability to hydrate itself, thereby competing for water in the extrudate matrix making it unavailable for the complete gelatinization of bambara and cassava starches. It has been postulated that specific volume increased when the degree of starch gelatinization increases (Tester \& Morrison, 1990). The regression coefficients indicated that the negative interactive effect of corn bran inclusion on the dietary fiber and cassava starch gelatinization was rather significant on the expansion ratio than the specific volume (Table 2).

The breaking force and BSI of the extrudates ranged from 3.95 to $36.45 \mathrm{~N}$ and 0.99 to $9.11 \mathrm{~N} / \mathrm{mm}$, respectively. The breaking force and BSI increased with increasing levels of cassava starch and corn bran inclusion (Figure 4). The ingredient combinations had significant $(p<0.05)$ positive linear effects on breaking force and BSI of the snacks (Table 2). The breaking force (hardness) is the peak force required for a probe or parallel blades to penetrate a product. The higher the value of the maximum force applied the harder is the the product.

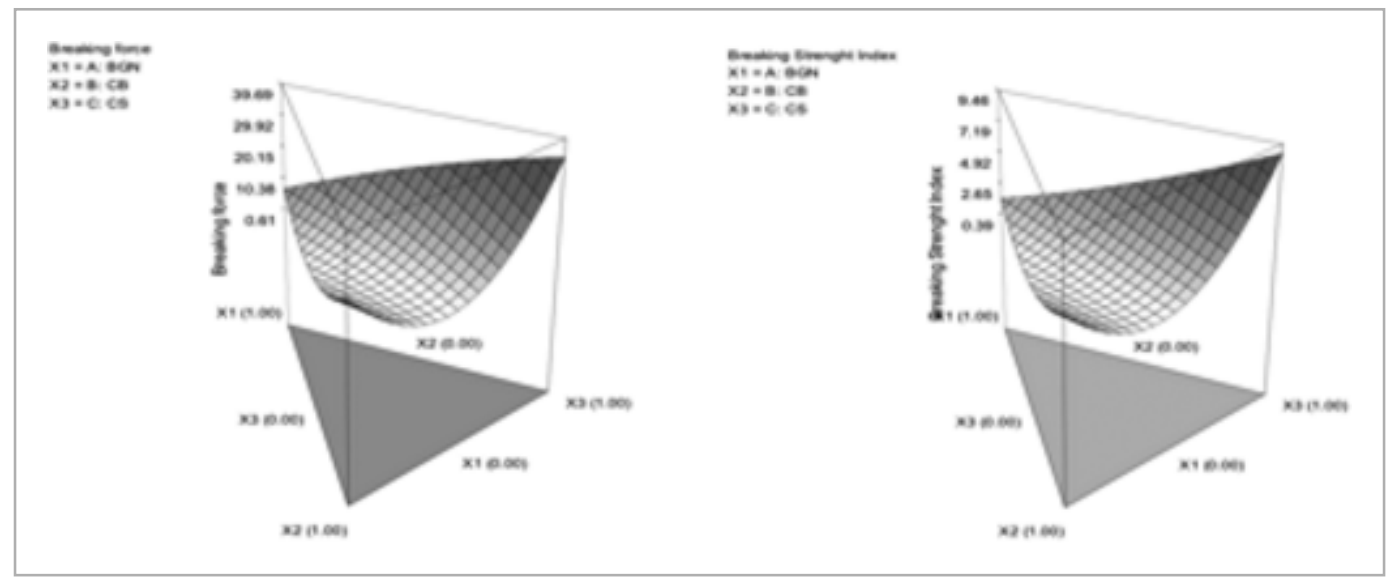

\section{Figure 4.}

Open in figure viewer

Surface plots showing breaking force and breaking strength index of bambara flour-corn brancassava starch extruded snacks

\subsection{Proximate composition of the extruded snacks}

Figure 5 presents the protein, moisture, fat, ash, carbohydrate, crude fiber, and total dietary fiber contents of the extruded snacks. There were significant differences in the protein, ash, carbohydrate, crude, and total dietary fiber of the snacks. The coefficient of regression analysis for the proximate composition of the extruded snacks is shown in Table 3. The ingredient combinations significantly $(p<0.05)$ had positive linear effects on the proximate composition of the snacks except fat, which was negatively affected by cassava starch. Bambara 
interactive effect on total dietary fiber. Moisture content of the snacks ranged from 5.40 to $10.80 \%$. The decrease in the moisture content with increasing levels of corn bran inclusion could be as a result of large air spaces in the corn bran particles thereby being unable to bind water hence, making the moisture to be easily driven off. The very low $R^{2}$ value $(0.35)$ and adj $R^{2}(-0.0585)$ compared to other proximate compositions indicated that the model may not be adequately used to predict the moisture content of the snacks. The protein content ranged from 3.26 to $17.62 \%$. Protein content increased and was highest at high level of bambara groundnut inclusion. This is a great potential for improving the nutritional quality of numerous snack products (Tiwari, Gunasekaren, Jaganmohan, Alsgusundaram, \& Tiwari, 2011). The fat content ranged from 0.68 to $10.35 \%$. Typically, cereals such as wheat and corn are low in oils (about $2 \%$ ), which is concentrated in the bran and is removed during milling so as to improve storage stability of flour. Extrusion can prevent free fatty acid release (causing rancidity) by denaturing hydrolytic enzymes (Camire, 1998). Ash content is an indication of the presence of minerals and in this work, it ranged from 0.54 to $3.45 \%$, which could be attributed to the high ash content of bambara groundnut flour and corn bran. The carbohydrate contents ranged from 60.56 to $85.03 \%$, which is expected and attributable to the cassava starch. This was also indicated by the significant positive interactive effect of bambara groungdut flour and cassava starch. Extruded snack products tend to be regarded as high glycaemicindex product (Capriles, Soares, Pinto E Silva, \& Areas, 2009; Onwulata et al., 2001). The crude fiber and total dietary fiber contents of the snacks ranged from 0.32 to $4.78 \%$ and 7.36 to $28.74 \%$, respectively. The increased crude fiber and total dietary fiber contents with increase in the levels of bambara groundnut flour and corn bran and decrease with increase in cassava starch level was due to the high fiber content of corn bran and bambara groundut flour. Dietary fiber tends to have detrimental effects on extrudate characteristics, decreasing the expansion ratio and increasing hardness and density (Onwulata et al., 2001). Total dietary fiber content of starchy foods might increase after heat processing due to the formation of enzyme-resistant starch during cooling of the products. 


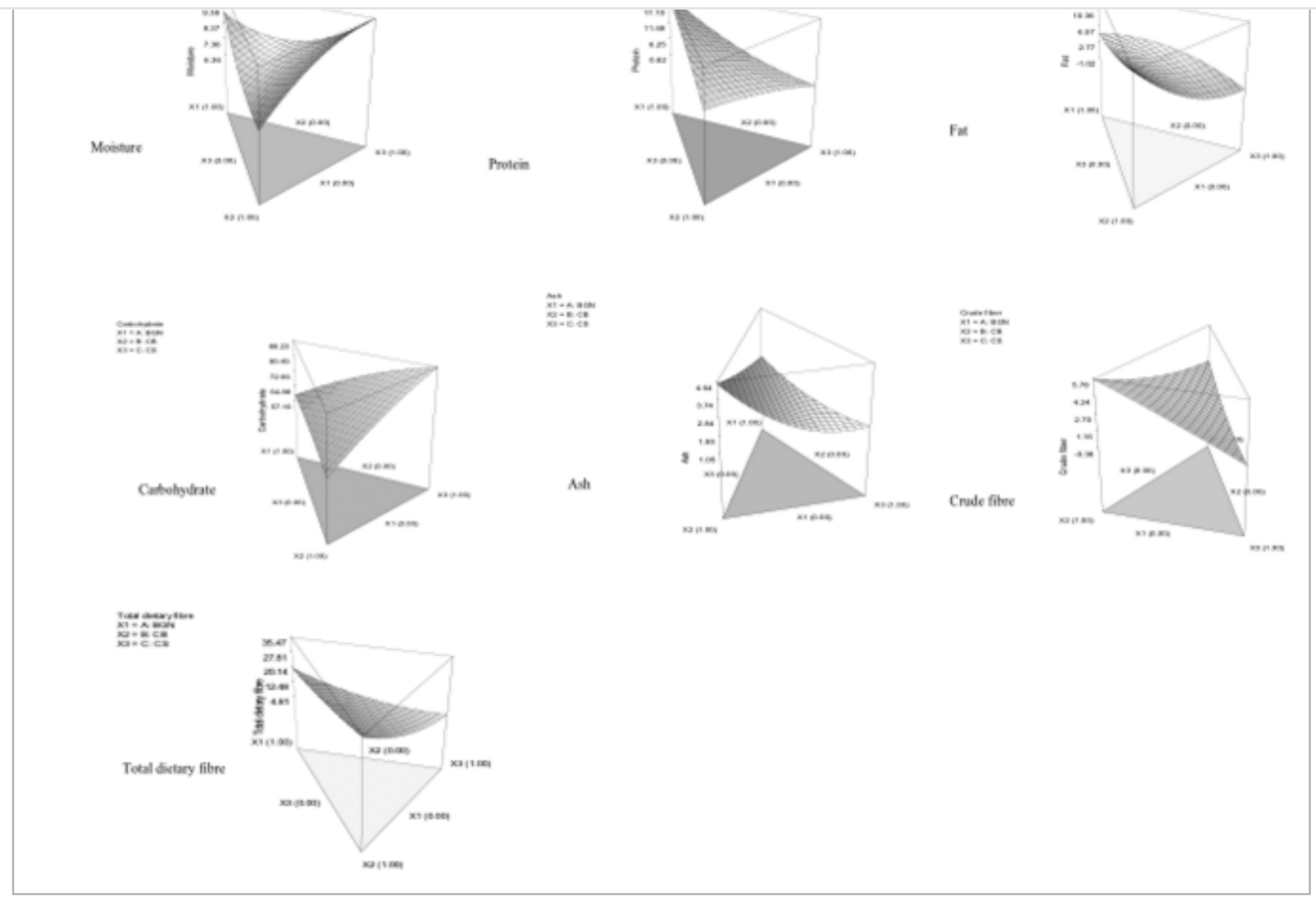

Figure 5.

Open in figure viewer

Surface plots showing proximate composition of bambara flour-corn bran-cassava starch extruded snacks

Table 3. Regression coefficients for the proximate composition of the extruded snacks

\begin{tabular}{|l|c|c|c|c|c|c|c|}
\hline Components & $Z_{\mathbf{1}}$ & $Z_{\mathbf{2}}$ & $Z_{\mathbf{3}}$ & $\mathbf{Z}_{\mathbf{4}}$ & $\mathbf{Z}_{\mathbf{5}}$ & $\mathbf{Z}_{\mathbf{6}}$ & $\mathbf{Z}_{\mathbf{7}}$ \\
\hline$X_{1}$ & $9.04^{*}$ & $21.10^{*}$ & $4.93^{*}$ & $2.37^{*}$ & $1.92^{*}$ & $60.61^{*}$ & $19.80^{*}$ \\
$X_{2}$ & $6.87^{*}$ & $9.71^{*}$ & $14.04^{*}$ & $5.78^{*}$ & $4.54^{*}$ & $59.02^{*}$ & $34.80^{*}$ \\
$X_{3}$ & $10.39^{*}$ & $0.82^{*}$ & $-1.02^{*}$ & $0.14^{*}$ & $1.41^{*}$ & $88.23^{*}$ & $5.62^{*}$ \\
$X_{1} X_{2}$ & -3.00 & 3.97 & -4.11 & -2.74 & -0.53 & 6.54 & -5.39 \\
$X_{1} X_{3}$ & -6.20 & -12.80 & 12.49 & -3.13 & -2.05 & $11.81^{*}$ & $-15.28^{*}$ \\
$X_{2} X_{3}$ & 3.25 & 5.35 & -15.29 & 0.46 & -4.39 & 10.75 & $-18.97^{*}$ \\
& & & & & & &
\end{tabular}




\begin{tabular}{|c|c|c|c|c|c|c|c|}
\hline$R^{2}$ & 0.3486 & 0.9452 & 0.6923 & 0.9853 & 0.7298 & 0.9946 & 0.9973 \\
\hline$F$ value & 0.86 & 27.58 & 3.60 & 106.89 & 4.32 & 291.99 & 582.71 \\
\hline$p>F$ & 0.5480 & $<0.0001$ & 0.0530 & $<0.0001$ & 0.0334 & $<0.0001$ & $<0.0001$ \\
\hline Pred $R^{2}$ & -0.8934 & 0.8155 & -0.0044 & 0.9520 & 0.1949 & 0.9837 & 0.9911 \\
\hline Adj $R^{2}$ & -0.0585 & 0.9109 & 0.5000 & 0.9760 & 0.5609 & 0.9911 & 0.9956 \\
\hline \multicolumn{8}{|c|}{$\begin{array}{l}X_{1} \text {, bambara flour; } X_{2} \text {, corn bran; } X_{3} \text {, cassava starch; } Z_{1} \text {, moisture; } Z_{2} \text {, protein; } Z_{3} \text {, fat; } Z_{4} \text {, crude fiber; } Z_{5} \text {, ash; } Z_{6} \\
\text { carbohydrate; } Z_{7} \text {, total dietary fiber. }\end{array}$} \\
\hline \multicolumn{8}{|c|}{ *Significant at $p<0.05$} \\
\hline
\end{tabular}

\section{Conclusion}

The physical properties and proximate composition of the extruded snack showed a great potential of utilizing bambara groundnut flour and corn bran for value added foods, providing rich and cheap sources of protein and dietary fiber from underutilized commodity (bambara groundnut) and waste to wealth (corn bran).

\section{Acknowledgment}

This article is one of the outputs of a project titled "Improving the livelihoods of smallholder cassava farmers through better access to growth markets (CassavaGmarkets)" sponsored by the European Commission Food Security Thematic Programme (FSTP) Component 1-Research and Technology. 